\title{
Using electronic mail communication and metacognitive instruction to improve mathematical problem solving
}

\author{
Bracha Kramarski and Adiva Liberman \\ School of Education, Bar-Ilan University, Ramat-Gan 52900, Israel; kramarb@mail.biu.ac.il
}

\begin{abstract}
The present study investigated the effects of e-mail communication between teachers and students embedded within metacognitive instruction on mathematical problem solving. Three learning environments are compared: (a) e-mail communication with metacognitive instruction (META+EMAIL); (b) e-mail communication without metacognitive instruction (EMAIL); and (c) face-to-face communication (CONT group).

Participants were 119 fifth-grade students (boys and girls), who practiced six weeks of problem solving on authentic tasks in three classes. Students who were exposed to e-mail conversation and metacognitive instruction (EMAIL+META) outperformed students who were not exposed to metacognitive instruction (EMAIL and CONT) on problem solving. The effects were observed on various aspects of solving authentic tasks: (a) processing information; (b) using mathematical strategies; and (c) using mathematical communcation. The EMAIL students outperformed the CONT students only on one criterion: Using mathematical strategies.
\end{abstract}

Key words: elementary education, conditions for learning, research, networks

\section{INTRODUCTION}

Interest in communication is both more widespread and more central to mathematics education reform efforts than ever before. The National Council of Teachers of Mathematics (2000) emphasises the importance of problem solving and communicating mathematical ideas, not simply providing isolated answers. The new reforms for teaching of mathematics

The original version of this chapter was revised: The copyright line was incorrect. This has been corrected. The Erratum to this chapter is available at DOI: 10.1007/978-0-387-35668-6_17 
redirect teachers to focus on problem solving within authentic contexts. From a motivational perspective, such tasks are challenging and relevant to the students' world and daily life (OECD 2000). Although authentic tasks are important, little is known at present about how to enhance students' ability to solve such tasks. The question, "What characteristics should a learning environment have to facilitate the construction of students' ability to solve authentic problems?" merits further research.

\subsection{Using electronic mail communication and metacognitive instruction}

One of the most immediate communication benefits networked computers offer is electronic mail. E-mail has the potential for becoming a near-universal source of communication within the next decades (Deaudelin and Richer 1999). It allows asynchronous exchanges and permits one-to-one as well as one-to-many communications. Of the two, teachers should take advantage of one-to-one communication because it makes up for the lack of student-teacher interpersonal communication, inevitable in the classroom context. It may be an important tool for providing individual support to students. However, that particular technology, as has been the case with prior technologies, raises the question about pedagogical approaches.

A review of pedagogical approaches shows that the majority emphasise the development of metacognition or learning-to-learn abilities. Many researchers (e.g., Butler and Winne 1995; Mevarech and Kramarski 1997) maintain that learning-to-learn abilities proved to be essential to the improvement of learning performances and problem solving. Butler and Winne (1995) describe Self Regulation Learning (SRL) as a style of activities for problem solving that includes: Evaluating goals, thinking of strategies and choosing the most appropriate strategy for solving the problem. The IMPROVE method (Mevarech and Kramarski 1997) emphasises the importance of providing each student with the opportunity to construct mathematical meaning by involving him/her in mathematical learning via the use of self questioning that focuses on: (a) comprehending the problem ("What is the problem all about"?); (b) constructing connections between previous and new knowledge ("What are the similarities/differences between the problem at hand and the problems you have solved in the past? and why?"); (c) use of strategies appropriate for solving the problem ("What are the strategies/tactics/principles appropriate for solving the problem and why?"); and in some studies also (d) reflecting on the processes and the solution ("What did I do wrong here?"; "Does the solution make sense?").

Generally speaking, researchers (e.g., Schoenfeld 1992; Mevarech and Kramarski 1997; Kramarski, Liberman, and Mevarech 2001) reported 
positive effects of metacognitive instruction on students' mathematical achievement. There is also evidence showing that the effects of metacognitive feedback in a computerised environment were more positive than the effects of result feedback on mathematical reasoning (Kramarski and Zeichner 2001). So we hypothesised that providing metacognitive instruction embedded in e-mail communication would exert more positive effects on students' problem solving than using e-mail communication, which in turn would exert more positive effects than face-to-face communication without metacognitive instruction.

\section{METHOD}

Participants, 119 fifth-grade students (boys and girls, mean age 10.4), practiced six weeks of problem solving in three classes. The EMAIL+META group $(n=40)$ was exposed to e-mail communication embedded with metacognitive instruction and the EMAIL class $(n=40)$ was exposed to e-mail communication without metacognitive instruction. The CONT class $(n=39)$ was exposed to face-to-face communication without metacognitive instruction and served as a control group.

\section{$2.1 \quad$ Treatments}

Students in all conditions practiced problem solving of three authentic tasks for four weeks ( 90 minutes a week) and they were asked to reflect by writing their decisions during the problem-solving process. The following is an example of such an authentic task:

The Hall Task: You have to arrange a Hall for a party in school. Here are three different price proposals for renting the Hall: The price is NIS 1,000 for renting the Hall, no matter how many people will arrive. The basic price for renting the Hall is NIS 400. But, if the number of participants will be more than 200, you have to pay NIS 3 more for each person. The basic price for renting the Hall is NIS 200 and in addition you have to pay NIS 3 for each participant. Decide which offer is most worthwhile. Explain your reasoning.

A full accurate answer regards correctly organizing the information by using tables, diagrams or algebraic expressions, making a correct suggestion based on the given information and providing verbal explanations to justify the suggestion. 
The study was implemented in pairs, as follows: Each student, in turn, read the task aloud, tried to solve it and explained his/her mathematical reasoning. Whenever there was no consensus, the students discussed the issue until the disagreement was resolved. Students were encouraged to talk about the task, explain it to each other, and approach it from different perspectives.

\subsubsection{E-mail communication}

The students who were exposed to EMAIL communication practiced problem solving authentic tasks once a week in the computer lab (90 minutes). They were encouraged to communicate with their teacher, who was called the "virtual teacher". They practised how to send/receive assignments and submit questions regarding the solution process, and how to send/open attachment files. They were also encouraged to ask the teacher for help when they encountered difficulties in understanding and correcting the solution, if needed, after receiving feedback by EMAIL from the teacher.

\subsubsection{Metacognitive instruction}

The metacognitive instruction was based on Mevarech's and Kramarski's (1997) IMPROVE technique. The method used four self-addressed metacognitive questions:

- Comprehension questions were designed to prompt students to reflect on the problem/task before solving it. In addressing a comprehension question, students had to read the problem/task aloud and describe the task in their own words. They tried to understand what the tasks/concepts mean and answered questions such as, "What is the problem/task all about?"; "What is the question?"; "What are the meanings of the mathematical concepts?"

- Connection questions were designed to prompt students to focus on similarities and differences between the problem/task they work on and the problem/task or set of problems/tasks that they had already solved such as, "How is this problem/task different from/similar to what you have already solved? Explain why."

- Strategic questions were designed to prompt students to consider which strategies are appropriate for solving the given problem/task and for what reasons. So students had to describe what strategy/tactic/ principle can be used in order to solve the problem/task, why the strategy/tactic/principle is most appropriate for solving the problem/task, and how to organize the information to solve the problem/task. 
- Reflection questions were designed to prompt students on their understanding and feelings during the solution process ( "What am I doing?"; "Does it make sense?"; "What difficulties/feelings I face in solving the task?"; "How can I verify the solution?"; "Can I use another approach for solving the task?").

Students used the metacognitive questions during their discourse in small group activities and in their written explanations when they solved the mathematical tasks. Teachers modelled the use of the metacognitive questions in their introductions, reviews and when they provided help. Students also studied according to the IMPROVE method and EMAIL communication described above, and were encouraged to use the metacognitive questions - comprehension, connection, strategic and reflection - in their communication with the "virtual teacher". The teachers used the metacognitive questions when they provided help in their e-mail messages.

\subsubsection{EMAIL condition}

Students in that class studied the same way as students in the EMAIL+META class but they were not exposed to the metacognitive instruction.

\subsubsection{Control condition}

Students studied the same way as students under the EMAIL+META and EMAIL conditions but they were not exposed to e-mail communication nor to metacognitive instruction. Students were asked to submit the solution of the authentic tasks in writing and to reflect on their solution process.

\section{MEASURES}

Two measures were used to assess students' mathematical problem solving: (a) a pre-test that focused on students' mathematical knowledge prior to the beginning of the study and (b) a post-test that assessed students' ability to solve authentic mathematical problems.

The 22-item multiple-choice item pre-test of basic factual knowledge and open-ended computation problems was administered to all students at the beginning of the school year and covered arithmetic knowledge taught prior to the beginning of the study. The following content appeared on the test: Whole numbers, fractions, decimals and percents. For each item students 
received a score of either 1 (correct answer) or 0 (incorrect answer), and a total score ranging from 0 to 22 (Kuder Richardson reliability coefficient was $=.87$ ).

The post-test consisted of an authentic task to assess students' ability to solve such tasks as shown in Figure 1.

Your classmates organize a party. The school will provide the soft drinks, and you are asked to order the pizza. The class budget is NIS 85.00. Of course, you want to order as many pizzas as you can. Here are proposals of three local pizza restaurants and their prices. Compare the prices and suggest the cheapest offer to the class treasurer. Write a report to the class treasurer in which you justify your suggestion.

\begin{tabular}{|c|c|c|c|c|}
\hline TYPE OF PIZZA & $\begin{array}{l}\text { PRICE } \\
\text { PIZZA }\end{array}$ & PER & DIAMETER & $\begin{array}{l}\text { PRICE FOR } \\
\text { SUPPLEMENTS }\end{array}$ \\
\hline \multicolumn{5}{|c|}{ PIZZA ВООМ } \\
\hline PERSONAL PIZZA & 3.50 & N.I.S & 15 & 4.00 N.I.S \\
\hline SMALL & 6.50 & N.I.S & 23 & 7.75 N.I.S \\
\hline MEDIUM & 9.50 & N.I.S & 30 & 11.00 N.I.S \\
\hline LARGE & 12.50 & N.I.S & 38 & 14.45 N.I.S \\
\hline EXTRA LARGE & 15.50 & N.I.S & 45 & 17.75 N.I.S \\
\hline \multicolumn{5}{|c|}{ SUPER PIZZA } \\
\hline SMALL & 8.65 & N.I.S & 30 & 9.95 N.I.S \\
\hline MEDIUM & 9.65 & N.I.S & 35 & 10.95 N.I.S \\
\hline LARGE & 11.65 & N.I.S & 40 & 12.95 N.I.S \\
\hline \multicolumn{5}{|c|}{ MC PIZZA } \\
\hline SMALL & 6.95 & N.I.S & 25 & N.I.S \\
\hline LARGE & 9.95 & N.I.S & 35 & 1.25 N.I.S \\
\hline
\end{tabular}

Figure 1. Authentic task to assess students' solutions

The Pizza Task is familiar to junior high school students, the mathematical data is rich and there is no ready-made algorithm for solution. It requires the use of a variety of sources of information (e.g., prices, size, number of supplements), and has many different correct solutions. The solvers must make computations, use different representations and apply knowledge regarding geometry, fractions and ratio.

Students' responses were scored on three criteria based on the model of Cai, Lane and Jakabcsin (1996) for analysing open-ended tasks: (a) processing information; (b) using mathematical strategies; and (c) using mathematical communication. Each criterion was scored between 0 (no response or incorrect response) to 5 (full correct response). A full, correct answer calls for organizing the information in a table, diagram, or an 
algebraic expression, making a correct suggestion based on the given information, and justifying the suggestion by explaining one's mathematical reasoning. Inter-judge reliability of four categories was .89 .

\section{RESULTS}

Table 1 presents the scores, and standard deviations on problem solving of the authentic tasks by time and treatment. A one way MANCOVA was carried out on the various measures of the authentic task with the pre-test scores used as a covariant.

Table 1. Mean scores and standard deviation on the pre-test and post-test by treatment

\begin{tabular}{|c|c|c|c|c|c|}
\hline & & $\begin{array}{l}\text { EMAIL + } \\
\text { META N }=28\end{array}$ & EMAIL $N=33$ & $\begin{array}{l}\text { CONTROL } \\
\mathrm{N}=36\end{array}$ & \\
\hline \multicolumn{6}{|l|}{ Pre-test } \\
\hline \multicolumn{6}{|l|}{ Prior } \\
\hline \multirow[t]{2}{*}{ knowledge } & M & 81.81 & 79.70 & 77.80 & $\begin{array}{l}F(2,94)=.05 \\
P>.05\end{array}$ \\
\hline & SD & 15.20 & 17.21 & 14.81 & \\
\hline \multicolumn{6}{|l|}{ Post-test } \\
\hline \multirow[t]{2}{*}{ task } & M & 44.01 & 30.16 & 25.22 & $\begin{array}{l}\mathrm{F}(2,93)=10.81 \\
\mathrm{P}<.0001\end{array}$ \\
\hline & SD & 20.78 & 18.8 & 12.28 & \\
\hline Adjusted M & & 38.95 & 32.05 & 27.82 & \\
\hline $\begin{array}{l}\text { Processing } \\
\text { information }\end{array}$ & M & 19.64 & 10.94 & 10.42 & $\begin{array}{l}\mathrm{F}(2,93)=12.38 \\
\mathrm{P}<.0001\end{array}$ \\
\hline & SD & 10.58 & 8.70 & 7.76 & \\
\hline $\begin{array}{l}\text { Adjusted M } \\
\text { Using } \\
\text { mathematical }\end{array}$ & & 18.86 & 11.58 & 10.38 & \\
\hline \multirow[t]{2}{*}{ strategies } & M & 16.52 & 10.42 & 5.49 & $\begin{array}{l}F(2,93)=19.58 \\
P<.0001\end{array}$ \\
\hline & SD & 10.79 & 8.05 & 5.58 & \\
\hline $\begin{array}{l}\text { Adjusted M } \\
\text { Using } \\
\text { mathematical } \\
\text { communicatic }\end{array}$ & & 15.79 & 11.01 & 5.46 & \\
\hline M & & 22.10 & 14,24 & 13.07 & $\begin{array}{l}F(2,93)=12.52 \\
P<.0001\end{array}$ \\
\hline SD & & 9.24 & 9.40 & 5.71 & \\
\hline $\begin{array}{l}\text { Adjusted M } \\
\text { Note. Range s }\end{array}$ & 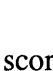 & 21.44 & 14.78 & 13.04 & \\
\hline
\end{tabular}


Results indicated that prior to the beginning of the study no significant differences were found between the students in the three treatments on their prior knowledge. Results of the post-test indicated that students who were exposed to the EMAIL+META condition significantly outperformed their counterparts (EMAIL and CONT classes) in solving the authentic task. As expected the EMAIL+META students benefited from the metacognitive instruction on the three criteria: Processing information, using mathematical strategies and using mathematical communication, but students in the EMAIL condition without metacognitive instruction significantly outperformed their counterparts in the CONT condition only on one criterion, using mathematical strategies. No significant differences were found between the EMAIL classes and the CONT classes on the other two criteria, processing information and using mathematical communication.

\section{DISCUSSION}

The present study raises several questions for future research. First, how can technology be utilised to enhance cognitive development? In the light of the constructivist approach, it seems that in order to utilise advanced technologies efficiently, students should be exposed to metacognitive instruction that enhances awareness, self-control, and self-monitoring of the cognitive processes. There may be a need to design metacognitive strategies that would be an integral part of the mathematical discourse. Such questioning may lead students to activate different levels of problem solving.

The findings are in line with other results that show that metacognitive instruction enhances mathematical problem solving as well as the ability to communicate mathematical reasoning in the classrooms (Kramarski 2000) and support other conclusions on the importance of integrating pedagogical uses with advanced technology, in particular metacognitive instruction (Deaudelin and Richer 1999; Kramarski and Zeichner 2001).

The results raise two main questions: (a) "What is the role of metacognitive instruction in enhancing different aspects of authentic task solutions?" and (b) "Why did the EMAIL students not outperform the CONT students on mathematical communication?"

The metacognitive self-addressed comprehension questions ("What is the problem all about?") probably guided students to look for all the relevant information, distinguish between the relevant and irrelevant information, and comprehend the entire task rather than parts of it. The connection questions ("How is this problem/task different/similar from what you have already solved?") might lead students to pay attention to all the information and the structure of the given task. So being trained to use the self-addressed 
questions may have led students to focus on the structural features of the task as well as on all the information given in the task.

The findings further showed that the metacognitive students were also better able to reorganize and process given information than their counterparts in the non-metacognitive condition, probably because the metacognitive instruction trained students to think about which strategies are appropriate for solving the task and why. By doing so, students suggested different kinds of representations, compared the strategies, and analysed each strategy.

Finally, it was found that the EMAIL+META students were better able to communicate their reasoning than their counterparts in the nonmetacognitive conditions, who were also encouraged to discuss their mathematical ideas and be involved in the mathematical discourse that took place in the small group. That finding indicates that using e-mail communication and face-to-face conversation are not sufficient for enhancing mathematical problem solving. Further research based on observations and e-mail discourse analysis may provide richer insight into our understanding of how students solve authentic tasks using electronic mail communication.

\section{REFERENCES}

Butler, D. L. and Winne, P. H. (1995) Feedback and self-regulated learning: A theoretical synthesis. Review of Educational Research 653 245-281.

Cai, J., Lane, S., and Jakabcsin, M. S. (1996) The role of open-ended tasks and holistic scoring rubrics: Assessing students' mathematical reasoning and communication. In P.C. Elliott and M. J. Kenney (eds.) Communication in Mathematics, K-12 and Beyond. New York: Academic Press 137-145.

Deaudelin, C. and Richer, A. (1999) A learning conversation approach integrating email: Its experiment to support the student learning process at college level. Paper presented at the $8^{\text {th }}$ annual EARLI Conference, Goteborg, Sweden.

Kramarski, B. (2000) The effects of different instructional methods on the ability to communicate mathematical reasoning. In Tadao Nakahara and Masataka Koyama (eds.) Proceedings of the $24^{\text {th }}$ Conference of the International Group for the Psychology of Mathematics Education, Hiroshima University: Hiroshima, Japan 1 167-171.

Kramarski, B., Mevarech, Z. R., and Liberman, A. (2001) The effects of multilevel - versus unilevel-metacognitive training on mathematical reasoning. Journal for Educational Research 945 292-300.

Kramarski, B. and Zeichner, O. (2001) Using technology to enhance mathematical reasoning: Effects of feedback and self-regulation learning. Educational Media International 38 2/3 7782.

Mevarech, Z. R. and Kramarski, B. (1997) IMPROVE: A multidimensional method for teaching mathematics in heterogeneous classrooms. American Educational Research Journal 342 365-395. 
National Council of Teachers of Mathematics. (2000) Principles and Standards for School Mathematics. Reston, VA: National Council of Teachers of Mathematics.

OECD. (2000) Measuring Students Knowledge and Skills. The PISA 2000 Assessment of Reading, Mathematical and Scientific Literacy. Paris: OECD.

Schoenfeld, A. H. (1992) Learning to think mathematically: Problem solving, metacognition, and sense making in mathematics. In D. A. Grouws (ed.) Handbook of Research on Mathematics Teaching and Learning. New York: MacMillan 165-197.

Symons, S. and Greene, C. (1993) Elaborative interrogation and children's learning of unfamiliar facts. Applied Cognitive Psychology 7 219-228.

Webb, N. M. (1991). Task-related verbal interaction and mathematics learning in small groups. Journal for Research in Mathematics Education 22 366-389.

\section{BIOGRAPHY}

Bracha Kramarski is an expert in mathematical education in different learning environments. Her main interests are the teaching of mathematics, new technologies, cognition and metacognition, and teacher training. She also developed programs for the teaching of mathematics in different environments - the development and management of a project, IMPROVE Method for teaching mathematics in classrooms, for example. She is currently Deputy Director of the School of Education and Head of the Teachers Training and InService Education at Bar-Ilan University, Israel.

Adiva Liberman is a research assistant and specializes in developing materials within the IMPROVE method. 